Portland State University

PDXScholar

\title{
The Assessment of Phonological Processes : A Comparison of Connected-Speech Samples and Single-Word Production Tests
}

Susan A. Pinkerton

Portland State University

Follow this and additional works at: https://pdxscholar.library.pdx.edu/open_access_etds

Part of the Speech and Hearing Science Commons

Let us know how access to this document benefits you.

Recommended Citation

Pinkerton, Susan A., "The Assessment of Phonological Processes : A Comparison of Connected-Speech Samples and Single-Word Production Tests" (1990). Dissertations and Theses. Paper 4191.

https://doi.org/10.15760/etd.6074

This Thesis is brought to you for free and open access. It has been accepted for inclusion in Dissertations and Theses by an authorized administrator of PDXScholar. Please contact us if we can make this document more accessible: pdxscholar@pdx.edu. 
AN ABSTRACT OF THE THESIS OF Susan A. Pinkerton for the Master of Science in Speech Communication: Speech and Hearing Sciences presented August 9, 1990.

Title: The Assessment of Phonological Processes: A Comparison of Connected-Speech Samples and Single-Word Production Tests.

APPROVED BY THE MEMBERS OF THE THESIS COMMITTEE:
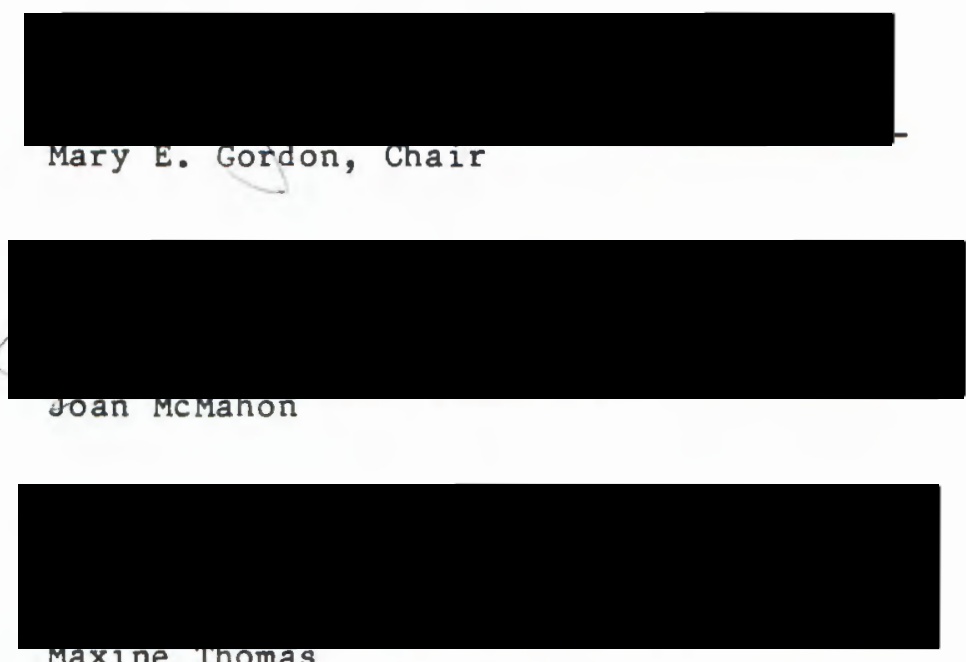

The purpose of this study was to determine if single-word elicitation procedures used in the assessment of phonological processes would have highly similar results to those obtained through connected speech. Connected speech sampling provides a medium for natural production with coarticulatory influence, but can be time-consuming and impractical for clinicians maintaining heavy caseloads or working 
with highly unintelligible children. Elicitation through single words requires less time than a connected-speech sample and may be more effective with highly unintelligible children because the context is known, but it lacks the influence of surrounding words. Given the inherent differences between these two methods of elicitation, knowledge of the relative effectiveness of single-word and connected-speech sampling may become an issue for clinicians operating under severe time constraints and requiring an efficient and effective means of assessing phonological processes.

The sample for this study comprised nine children, aged 4 years 1 month to 6 years 1 month, selected from speech, language, and hearing clinics within the Portland metropolitan area. Each subject exhibited a phonological process disorder of moderate or greater severity. Additional selection criteria included normal unilateral hearing and the absence of documented neuromuscular impairment. Each subject was administered two assessment instruments. The Assessment of Phonological Processes - Revised (APP-R) (Hodson, 1986) was used to establish the presence of a phonological process disorder meeting eligibility criteria (moderate or greater severity) and the GoldmanFristoe Test of Articulation (GFTA) (Goldman and Fristoe, 1986) "Sounds-in-Words" and "Sounds-in-Sentences" subtests were administered to elicit single-word and connected-speech samples.

The two types of speech samples were then evaluated by the Programs to Examine Phonetic and Phonologic Evaluation Records (PEPPER) (Shriberg, 1986) to determine the percentages of occurrence for each phonological process. Each subject's production of 
phonological processes was assigned a severity rating from 1 to 4 , and resulting values were statistically compared utilizing the Pearson $\underline{r}$ Product-Moment Correlation Coefficient (Pearson $\underline{r}$ ). Four of the nine phonological processes (unstressed syllable deletion, velar fronting, final consonant deletion, and palatal fronting) were found to be related sufficiently to be statistically significant at the $p<.05$ leve 1 with Pearson $\underline{r}^{\prime}$ 's ranging from .66 to .90. Two processes, initial consonant deletion and assimilation, showed no variance and thus could not be compared with the Pearson $\underline{r}$. The three remaining processes (stopping, liquid simplification, and cluster reduction) were not found to be related at a statistically significant level.

The Pearson $\underline{r}$ computation was not always supported by a visual evaluation. Upon thorough analysis, it became apparent that the limitation of the subjects to individuals exhibiting phonological processes of a moderate or greater severity resulted in a corpus of data so homogeneous that the relevance of the Pearson $\underline{r}$ correlation was diminished.

On the basis of a combined Pearson $\underline{r}$ and visual appraisal, the significance of the similarities between the single-word and connected-speech sampling methods became more apparent. For six of the nine processes, the single-word samples produced assessments of the incidence of phonological processes similar to that identified by the connected-speech sample. Although the accuracy of the singleword method was not as great for the three remaining processes, 
results were sufficiently comparable to provide clinicians with confidence that single-word elicitation provides an acceptable mode of assessment in most instances. 
THE ASSESSMENT OF PHONOLOGICAL PROCESSES: A COMPARISON OF CONNECTED-SPEECH SAMPLES AND SINGLE-WORD

PRODUCTION TESTS

by

SUSAN A. PINKERTON

A thesis submitted in partial fulfillment of the requirements for the degree of

\author{
MASTER OF SCIENCE \\ in \\ SPEECH COMMUNICATION: \\ SPEECH AND HEARING SCIENCES
}

Portland State University

1991 
TO THE OFFICE OF GRADUATE STUDIES:

The members of the Committee approve the thesis of Susan A. Pinkerton presented August 9, 1990.
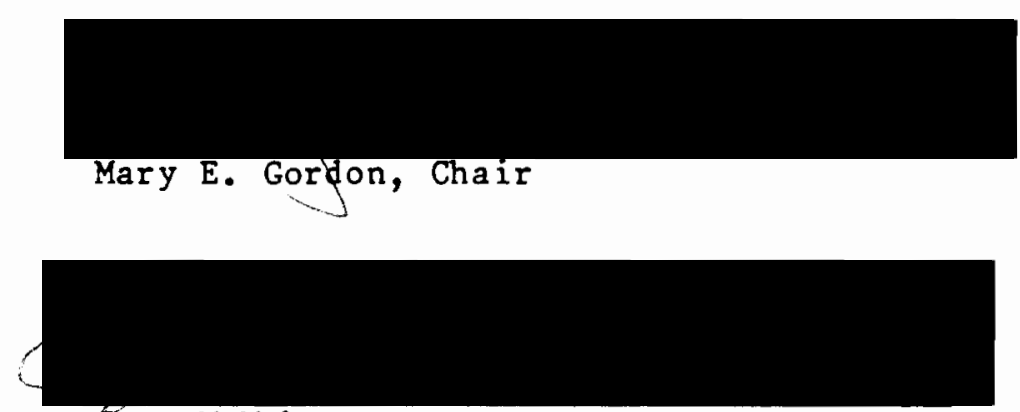

Joan McMahon

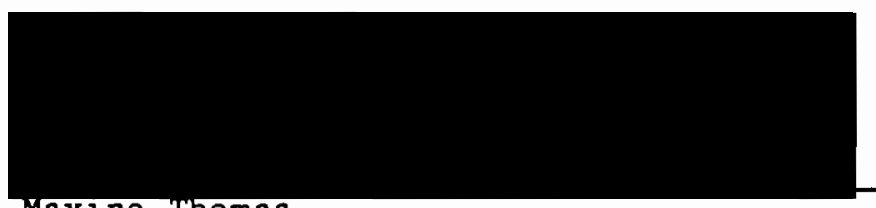

APPROVED:

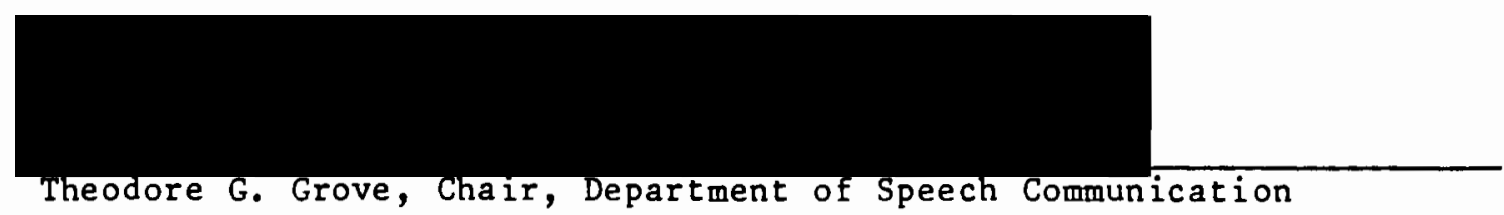

C. Wriliaul savery, Interlm vice provost for Graduate studies and Research 


\section{ACKNOWLEDGMENTS}

I wish to express my sincerest gratitude to the members of my committee, Mary E. Gordon, Joan McMahon, and Maxine Thomas, for the ir thoughtful assistance and valuable input. A special note of appreciation is extended to Mary for the knowledgeable guidance and committed effort she provided from the inception to completion of this project.

I would also like to thank Karen Jenkins, who assisted me in locating a number of the subjects which were used in this study, and Dana Hamburg, who gave up many hours of her summer to serve as judge of reliability in this research.

To my husband Jim and daughter Melissa - thank you so much for the love and consideration you have shown me; your support has made this so much easier. 
TABLE OF CONTENTS

PAGE

ACKNOWLE DGMENTS

ii i

LIST OF TABLES

vi

CHAPTE R

I INTRODUCTION ..................... 1

Statement of Purpose . . . . . . . . . 2

Definitions .............. 3

II REVIEW OF THE LITERATURE ............. 6

Phonological Processes........... 6

Speech Sample Collection . . . . . . . . . 9

Phonological Process Analysis ......... I 11

Tests of Phonological Processes

Connected-Speech Samples

Single-Word Articulation Tests

III METHODS . . . . . . . . . . . . . .

Subjects................ . . 19

Instrumentation . . . . . . . . . 20

Procedures ................ . . 21

Testing Environment

Test Administration

Reliability

Data Measurement and Analysis ......... 
Results ............... 27

Discussion .............. . . 34

Initial Consonant Deletion and Assimilation

Initial Consonant Deletion

Assimilation

Stopping

Liquid Simplification

Cluster Reduction

Unstressed Syllable Deletion

Velar Fronting

Final Consonant Deletion

Palatal Fronting

Pearson $\underline{r}$

Conclusions

$\nabla$

SUMMARY AND IMPLICATION

48

Summary ............... . 4 48

Implications .............. 50

Clinical

Research

REFERENCES

S

APPENDICES

A CONSENT FORM FOR SUBJECT PARTICIPATION . . . . . . 56

B GOLDMAN-FRISTOE TEST OF ARTICULATION - SOUNDS-IN-WORDS SUBTEST . . . . . . . . . . . . . . . .

C GOLDMAN-FRISTOE TEST OF ARTICULATION - SOUNDS-INSENTENCES SUBTEST ................. 60

D SEX, AGE, AND APP-R SCORES OF THE NINE SUBJECTS . . . . 66 


\section{LIST OF TABLES}

TABLE

PAGE

I Rating Scales Corresponding to Percentage of

Occurrence Intervals . . . . . . . . .

II Percentage of Occurrence, Severity Rating, and

Pearson $\underline{r}$ Correlation for Initial Consonant

Deletion in Two Sampling Conditions . . . . .

II Percentage of Occurrence, Severity Rating, and

Pearson I Correlation for Assimilation in Two

Sampling Conditions . . . . . . . . . . .

IV Percentage of Occurrence, Severity Rating, and

Pearson $\underline{r}$ Correlation for stopping in Two

Sampling Conditions . . . . . . . . . 30

$V$ Percentage of Occurrence, Severity Rating, and

Pearson $\underline{r}$ Correlation for Liquid Simplification

in Two Sampling Conditions . . . . . . . . 30

VI Percentage of Occurrence, Severity Rating, and

Pearson $\underline{r}$ Correlation for Cluster Reduction

in Two Sampling Conditions . . . . . . . . 31

VII Percentage of Occurrence, Severity Rating, and

Pearson $\underline{r}$ Correlation for Unstressed Syllable

Deletion in Two Sampling Conditions . . . . . 
VIII Percentage of Occurrence, Severity Rating, and

Pearson $\underline{r}$ Correlation for Velar Fronting in

Two Sampling Conditions ...........

IX Percentage of Occurrence, Severity Rating, and

Pearson $\underline{r}$ Correlation for Final Consonant Deletion

in Two Sampling Conditions..........

$X$ Percentage of Occurrence, Severity Rating, and

Pearson $\underline{r}$ Correlation for Palatal Fronting

in Two Sampling Conditions ..........

XI A Comparison of the Pearson $\underline{r}$ Correlations Calculated on Assigned Severity Ratings and Actual Percentages of Occurrence in Two Sampling Conditions.. 


\section{CHAPTER I}

\section{INTRODUCTION}

In the last 15 years, researchers studying speech sound disorders in children have diverged from an approach focused primarily on the motoric aspects of speech to one which also considers the rules or "processes" which govern the phonologic modality of language (Benjamin \& Greenwood, 1983). During this period of transition, however, disagreement has occurred regarding the most effective method with which to elicit samples of speech for assessment purposes.

Two of the more common procedures in use today for the analysis of phonological processes are connected-speech samples and single-word articulation tests (Bankson \& Bernthal, 1983; Stoe1-Gammon \& Dunn, 1985). Connected-speech sampling, a linguistically-based procedure (Bankson \& Bernthal, 1983), assesses speech production in a conversational or "continuous" context. It provides a medium for natural production with inherent coarticulatory characteristics (Garber, 1986; Shriberg \& Kwiatkowski, 1980), but can be time consuming and at times impractical for the clinician maintaining a heavy caseload and working with highly unintelligible children (Andrews \& Fey, 1986; Bankson \& Berntha1, 1983; Edwards, 1983; Hodson \& Paden, 1983; Klein, 1984). Single-word articulation testing, a more traditional method of assessment, analyzes speech through the production of isolated words. 
It requires less time to administer than a connected-speech sample (Paden \& Moss, 1985) and may be more effective with highly unintelligible children due to the known context in a word 1 ist (Hodson \& Paden, 1983) but it does sacrifice the influence of surrounding words on individual sound production.

While many practicing clinicians acknowledge that linguisticallybased assessment methods may provide a more complete understanding of their clients' phonological systems, acceptance for many has remained at the theoretical level due to time constraints surrounding administration and assessment (Bankson \& Bernthal, 1983). These contrasting points become an issue when clinicians maintaining heavy caseloads require an efficient and effective means of assessing phonological processes. Knowledge of the relative effectiveness of single-word and connected-speech sampling would provide clinicians with the information necessary to make informed assessment procedure selections.

\section{STATEMENT OF PURPOSE}

The purpose of this study was to determine if single-word elicitation procedures used in the assessment of phonological processes would have highly similar results to those obtained through connected speech.

The research question for this study is: Will the assessment of phonological processes elicited through single words and through connected speech identify an individual process as having the same degree of severity? 


\section{DEFINITIONS}

Defined below are terms which are operational for this study.

Affricate. Consonant sounds which are initiated with a stop and terminated with a fricative, i.e., $|t / f|(c h)$ and $\left|d J^{\prime}\right|(j)$.

Alveolar. Consonant sounds produced through contact of the tongue and upper dental ridge (alveolar ridge), i.e., $/ t /, / d /, / n /$, $/ \mathrm{s} /, / 2 /, / 1 /$, and sometimes $/ \mathrm{r} /$.

Assimilation - Progressive and Regressive. Adaptation of one or more phonemes within a word to match or make the production features (voice, place, manner) more similar to another phoneme within the word. In progressive assimilation, the production is influenced by a preceding phoneme, e.g., /mab / (mab) for /moet/ (mat). In regressive assimilation, the production is influenced by a phoneme which follows, e.g., /dudz/ (judge) for /bvd / (budge). This process is also referred to as "harmony."

cluster. Two or more consonants in approximation to each other without vowel separation. May be abutting consonants or consonant blends.

Cluster Reduction. Omission of one or more segments within a consonant cluster, including reduction of consonant blends, e.g., /bu/ (boo) for /blu/ (blue) and deletion of one or more abutting consonants, e.g., /bə2kIt/ (bakit) for /b xeskIt/ (basket).

Coarticulation. Influence of one phoneme on another in terms of the way it is produced.

Connected Speech. Speech production comprised of a sequence of two or more words. 
Continuant. Speech sounds produced with a continuous flow of air while the articulators maintain a constant position, e.g., /s/ and $/ E /$.

Final Consonant Deletion. Omission of a final consonant segment, e.g., /do/ (dah) for $/ \mathrm{d} g g /(\mathrm{dog})$.

Fricative. Continuant consonant sounds produced by forcing the air stream through a constricted opening, e.g., teeth and lower lip $(/ \mathrm{f} /)$, tongue and teeth $[/ \theta /(\mathrm{th})]$, and narrow groove at tip of tongue $(/ \mathrm{s} /)$.

Glide. Consonant sounds which are produced through the movement of the articulators as opposed to static placement, i.e., /w/, /1/, and $/ \mathrm{j} /$.

Initial Consonant Deletion. Omission of an initial consonant segment, e.g., /o1/(a11) for /bol/ (bal1).

Liquid. Consonant sounds $/ 1 /$ and $/ \mathrm{r} /$ produced in vowel or syllabic form, e.g., /bat $1 /$ (bottle) and /wat $\$$ (water); also known as semi vowe 1 .

Liquid Simplification. Substitution of vowe $1, / w /$, or $/ j /$ for

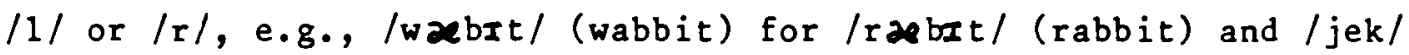
(yake) for /lek/ (lake).

Nasa1. Consonant sounds produced by lowering the velum (soft palate) and occluding the oral cavity, thereby directing the airflow through the nasal passage, e.g., /m/, /n/, and $/ \eta /$

Natural Process. Sound changes in speech production which meet the criteria of (a) a simplification of a more complex articulatory structure and (b) a universal occurrence in the languages of the world. 
Palatal. Consonant sounds produced by the tongue approximating the hard palate, i.e., $/ \mathrm{J} /,|\mathrm{s} /| d, z /, \mid t /, / \mathrm{j} /$, and sometimes $/ \mathrm{r} /$.

Palatal Fronting. Replacement of palatal consonants $(/ 5 /, 13 /$, $1 t \rho$, or $\mid d / /$ ) with a more anterior production (alveolar, linguadental, bilabial), e.g., /sep/ (sape) for / $/$ ep/ (shape) and /piz/ (peas) for $\left|t \int j i z\right|$ (cheese).

Phonological Process. Systematic simplification or alteration of the standard adult production of speech sounds.

Single Word Production. Speech production comprised of single words in isolation.

Stop. Consonant sounds produced through the interruption of air flow as a result of the closure of the oral cavity, i.e., $/ \mathrm{p} /, / \mathrm{b} /$, $/ \mathrm{t} /, / \mathrm{d} /, / \mathrm{k} /, / \mathrm{g} /$. Known as a plosive when the oral pressure is released suddently.

Stopping. Phonological process involving the substitution of stop consonants for continuant consonants, e.g., /mst/ (mit) for /mrs/ (miss) and /d2pm/ (dam) for $/ \mathrm{d} \zeta \not 2 m /(j a m)$.

Unstressed Syllable Deletion. Omission of a syllable in its entirety. Many procedures view syllable deletion processes in terms of omission of "unstressed" or "weak" syllables.

Velar. Consonant sounds produced with approximation of the back of tongue and the velum, i.e., $/ \mathrm{k} /, / \mathrm{g} /, \mid \eta /$.

Velar Fronting. Substitution of alveolar consonants $(/ \mathrm{t} / \mathrm{d} / \mathrm{d} /$, and $/ \mathrm{n} /$ ) for velar consonants $(/ \mathrm{k} /, / \mathrm{g} /$, and $/ \mathrm{g} /)$. 
CHAPTER II

REVIEW OF THE LITERATURE

\section{PHONOLOGICAL PROCESSES}

Historically, researchers and clinicians have regarded speech sound disorders primarily as substitutions involving individual phonemes or phoneme segments and have directed little attention to the developmental patterns of sound alterations and the manner in which those substitutions are interrelated. In 1969, however, Stampe proposed that children maintain an innate "natural phonology" in which they make general changes which facilitate the simplification of speech production, thereby allowing for a closer approximation of the adult model. Stampe noted that these changes, which he termed "phonological processes" (referred to as "natural processes" by Shriberg and Kwiatkowski (1980)) are both universal across languages and consistent in their order of appearance in children's phonological development. As children's phonology continues to develop, he contended, the innate processes are gradually suppressed as the adult form emerges. Phonological processes, then, came to be known as the systematic simplifications or alterations utilized by children in their attempt to produce standard adult speech sounds (Hodson \& Paden, 1983 ; Stampe, 1969 ; Weiss, Gordon, \& Li1lywhite, 1987). 
While the presence of phonological processes is normal in the developing phonology of children, normative data are limited regarding the expected age levels at which processes cease to appear (Weiss, Gordon, \& Lillywhite, 1987). Shriberg and Kwiatkowski (1980) suggest that all processes generally disappear between the ages of $1 \frac{1}{2}$ and 4 years, with occasional occurrences persisting beyond this time. Ingram (1983) noted that phonological disorders may be broadly organized into three major categories: (a) syllable structure processes, (b) assimilatory processes, and (c) substitution processes. Syllable structure processes simplify or reduce adult productions into less complex syllable shapes, such as deletion of final consonants or omission of one or more segments comprising a consonant cluster. Assimilatory processes involve those simplifications in which one portion of a word is produced to approximate or become more like another segment in the word, such as /dot/ (dote) for /got/ (goat). Substitution processes involve the replacement of one class of sounds for another, such as replacing fricatives with stops, or velars with alveolars.

Beyond these broad categories, however, the specific number of processes examined by researchers vary from one assessment instrument to the next, ranging from 8 to 42 phonological processes considered. The Programs to Examine Phonetic and Phonologic Evaluation Records (PEPPER) (Shriberg, 1986), a computer software analysis instrument, examines a total of nine processes, including eight "natural" processes (progressive and regressive assimilation, cluster reduction, final consonant deletion, liquid simplification, palatal fronting, 
stopping, unstressed syllable deletion, and velar fronting) and one (initial consonant deletion) which occurs with less frequency and is therefore considered not to be natural. These processes are described below as they are viewed and analyzed by the PEPPER.

Assimilation is the adaptation of one or more phonemes within a word to match or make the feature(s) (voice, place, manner) more similar to another phoneme within the word. In progressive assimilation, production is influenced by a preceding phoneme, such as /m $2 b /$ (mab) for /mat/ (mat). In regressive assimilation, production is influenced by a phoneme which follows, such as ldynd $/$ (judge) for /bndz/ (budge).

Cluster reduction is the omission of one or more segments within a consonant cluster. This includes reduction of blends, such as /bu/ (boo) for /blu/ (blue) and deletion of one or more abutting consonants, such as /baekIt/ (bakit) for /baskIt/ (basket).

Final consonant deletion is the omission of the final consonant segment, such as $/ \mathrm{d} J /(\mathrm{dah})$ for $/ \mathrm{d} J \mathrm{~g} /(\mathrm{dog}$ ) or $/ \mathrm{bo} /$ (bow) for /bon/ (bone).

Initial consonant deletion is the omission of the initial consonant segment in a word, such as $/ 21 /$ (a11) for /bol/ (bal1) or / $/ 2$ / (oye) for $/$ tJI/ for (toy).

Liquid simplification involves the substitution of a vowe $1, / w /$, or $/ \mathrm{j} /$ for $/ 1 /$ or $/ \mathrm{r} /$, such as $/ \mathrm{w} 20 \mathrm{br} t /$ (wabbit) for $/ \mathrm{r} 2 \mathrm{~b} z \mathrm{t} /$ (rabbit) and /jek/ (yake) for /lek/ (lake).

Palatal fronting involves the replacement of palatal consonants $(1 / 1,1 /, 1 t / /$, and $/ f /)$, with alveolar, lingua-dental, or bilabial 
productions which are more anterior in production. Examples include /sep/ (sape) for $/ \sqrt{e p} /$ and $/ p i z /$ (peas) for $/ t \int i z /$ (cheese).

Stopping involves the substitution of stop consonants $(/ \mathrm{p} /, / \mathrm{b} /$, $/ \mathrm{t} /, / \mathrm{d} /, / \mathrm{k} /, / \mathrm{g} /$ ) for continuant consonants (fricative or affricate), such as /mat/(mit) for / / $\mathrm{ms} /$ (miss) and /dxom/ (dam) for $/ d j \times m /(j a m)$.

Unstressed syllable deletion is the omission of a syllable in its entirety. While many instruments code only those simplifications involving the omission of a weak or unstressed syllable, Shriberg (1986) stated he "extends this rule to include any syllable deletion, regardless of stress" (p. 144). Examples include/meto/ (mato) for /tomato/ (tomato) and /naena/ (nana) for /banzeno/ (banana).

Velar fronting involves the substitution of alveolar consonants $(/ \mathrm{t} /$ and $/ \mathrm{d} /)$ for velar consonants $(/ \mathrm{k} /$ and $/ \mathrm{g} /)$, such as $/$ tek/ (take) for /kek/ (cake) and / dod/ (dood) for /gerd/ (good).

\section{SPEECH SAMPLE COLLECTION}

Speech samples are acquired in the form of connected speech or single words. Within these two broad categories, however, speech may be elicited with varying degrees of examiner control, determined by the subject's abilities and the desired focus of the individual examiner.

Shriberg and Kwiatkowski (1985) outlined five levels of connected-speech sampling, listed as follows in order of the least to greatest amount of examiner direction: (a) free, (b) story, (c) routine, (d) interview, and (e) scripted. The free procedure is child- 
directed in terms of materials used and conversational topic; examiner coments are 1 imited to non-directive observations. Within the story procedure, the examiner maintains indirect control of the context by selecting the materials to be used while the subject selects the conversational topic as related to the materials; examiner comments are 1 imited to non-directive observations. Facilitation of the routines procedure is more flexible in that the examiner selects the materials to be used while either the child or the examiner determines the conversational topic, which may or may not be related to the materials at hand; examiner comments and questions may be used to prompt subject verbalizations. Within the interview procedure, no materials are used and either the subject or the examiner may determine the conversational topic; the examiner may ask questions and probe for further verbalizations. The scripted procedure allows the examiner to maintain nearly complete control over the conversational content by managing material selection and utilizing a script of questions related to the materials at hand. Weiner (1979) developed an assessment procedure for connectedspeech sampling through elicitation of delayed imitation speech. With the support of action pictures, the examiner makes a prescribed comment regarding the activity depicted and subsequently poses a question which prompts an imitation of the examiner's statement. Single-word speech samples acquired for the analysis of phonological processes are generally elicited through the naming of objects (APP-R) (Hodson, 1986) and pictures (GFTA) (Goldman \& Fristoe, 1986) 
and delayed imitation tasks (PPA) (Weiner, 1979). Procedures for the $A P P-R$, GFTA, and PPA are outlined in the following section.

\section{PHONOLOGICAL PROCESS ANALYSIS}

Tests of Phonological Processes

According to Edwards (1983), the application of phonologically based theory was limited until the publication in 1976 of Ingram's book Phonological Disability in Children; subsequently, numerous assessment instruments based on phonological considerations have been developed. Although similar in their philosophy of assessment, they differ from one another in terms of their approach, including the number and type of processes assessed, terms used to define or describe a given process, and the method of speech sample collection (Edwards, 1983; Hodson \& Paden, 1983).

The Phonological Process Analysis (PPA) (Weiner, 1979) was the first assessment instrument to be published which considered phonological processes. Utilizing picture stimuli, it elicits delayed imitation responses, in both connected speech (phrases) and single words, which provide a speech sample from which 16 phonological processes are examined. Administration of this procedure is relatively controlled; the examiner provides a short statement about a picture followed by a question which prompts the child to respond with an imitation of the examiner's model.

The Assessment of Phonological Processes - Revised (APP- $R$ ) (Hodson, 1986) utilizes three-dimensional objects which are spontaneously named by the child in single-word responses, providing a 
corpus of speech production from which 42 phonological processes are examined. Although the authors described it as being a relatively free, client-directed procedure, the only responses evaluated are those corresponding directly to the test stimuli.

The Khan-Lewis Phonological Analysis (KLPA) (Khan \& Lewis, 1986) evaluates the production of 15 phonological processes. Serving as an overlay assessment device, it utilizes the responses elicited though the administration of the "Sounds-in-Words" subtest of the GoldmanFristoe Test of Articulation (GFTA) (Goldman \& Fristoe, 1986), and codes the data in terms of phonological processes.

The Natural Process Analysis (NPA) (Shriberg \& Kwiatkowski, 1980) assesses children's use of eight processes through connectedspeech sampling. This assessment instrument differs from many of the other phonologically-based procedures in that connected-speech sampling is utilized, as opposed to imitation or single-word naming activities, and limits the evaluation to those "natural" processes which result in a simplification and are found universally in phonological development; processes considered to be non-natural, such as lateralization or glottal replacement, are not assessed with this instrument.

The Procedures for the Phonological Analysis of Children's

Language (PPACL) (Ingram, 1981) assesses 27 phonological processes through any elicitation means selected by the clinician. The author states that the manner of elicitation is not critical, implying that connected-speech sampling and single-word responses to articulation tests provide equally valid results. 
Connected-Speech Samples

During the last 20 years, linguistic and coarticulatory considerations have had increasing influence on the clinician wishing to select the optimal assessment procedure for children with severe articulation and phonological process disorders (Bankson \& Bernthal, 1983; Benjamin \& Greenwood, 1983; Edwards, 1983; Garn-Nunn, 1986; Ingram, 1983). Speech sound errors, once assessed as isolated units of sound production, began to be analyzed in terms of the segmental relationships found in connected speech (Bankson \& Bernthal, 1983; DuBois \& Bernthal, 1978).

Darley and Spriestersbach (1978) underlined the importance of considering coarticulatory factors when assessing speech production, stating "it is unsafe to assume that a speaker's articulation of phonemes in the one-word responses elicited by a picture articulation test is representative of his or her articulation generally" (p. 241). Once could not infer, they stated, that a single phoneme is a valid representation of speech in general or that the same degree of articulatory competency found in the production of a single word could be maintained in connected speech. Johnson, Winney, and Pederson (1980) concurred with this premise, suggesting that single-word assessment procedures provide an opportunity for greater articulomotor planning, allowing for more focused and, therefore, more accurate speech production. Comparing three methods of eliciting articulatory responses (connected speech, modeled connected speech, and spontaneous picture naming), DuBois and Bernthal (1978) observed that their 18 subjects, $4: 3$ to $6: 2$ years of age, tended to decrease their speaking 
rates during spontaneous picture naming tasks, lending support to the premise that single-word production is performed in a more deliberate manner than is connected speech.

In their 1970 study, Faircloth and Faircloth noted that their 11-year-old subject, described as having a "severe articulation problem," demonstrated more syllable reduction errors during connected speech and that isolated responses were "consistently judged to be more intelligible" (p. 61) despite the fact they contained errors of omission, substitution, and distortion. Shriberg and Kwiatkowski (1980) agreed that connected-speech sampling provides a more accurate assessment of speech production, stating "phonological processes appear to be sensitive to complex linguistic and extralinguistic factors associated with mode of elicitation" (p. 8). Tests of articulation, they maintained, contain complex canonical forms which may not normally be produced by a child in connected speech, and could result in the use of simplification processes. They were in agreement, as we11, that the production of single words does not allow for the influence of proximal sounds inherent in connected speech. Paul and Shriberg (1982) supported these assertions, noting that syntactical factors affect the production of natural processes. In addition to the coarticulatory considerations mentioned, researchers have suggested that conversational production provides a medium with which to observe overall intelligibility and variability of children's speech, and that this very characteristic demonstrates the face validity of the procedure since the utility of speech is the sample of interest (Bankson \& Bernthal, 1983). Garber (1986) 
suggested that single-word articulation tests cannot claim such validity, in that "traditional phonological testing methods were not designed to examine the rule-governed behaviors operating within children's linguistic systems and thus do not provide a comprehensive description of the phonological system" ( $p .253$ ) as would a connected-speech sample which provides the influence of "context sensitive phonological rules" (p. 253).

In their study comparing the use of single words and connected speech in the assessment of 35 children, ages $3: 7$ to $9: 5$ years, with "articulation defects," Johnson, Winney, and Pederson (1980) demonstrated that connected speech identified more total errors than did single-word elicitation, revealed errors not observed in isolated word production, and resulted in a significantly greater number of omission errors than was produced in single words. They noted as well that 36 percent of the errors exhibited in connected speech were produced correctly by subjects when assessed through single-word elicitation. Klein (1984) found similar results in the examination of ten phonologically impaired children. Of the ten subjects included in her study, nine produced some processes in connected speech which had not been observed in isolated word production. In addition, of the 45 phonological processes noted in these subjects, 21 processes identified through connected speech were not detected through singleword elicitation. 
Single-Word Articulation Tests

Not all within the field agree with the necessity for, or even the desirability of, linguistic contexts when assessing disordered speech production. For the reticent or highly unintelligible child, assessment through single-word elicitation may be the only means by which a clinician is able to examine the sound productions of a child (Andrews \& Fey, 1986; Bankson \& Berntha1, 1983; Edwards, 1983; Hodson \& Paden, 1983; Paden \& Moss, 1985; Stoel-Gammon \& Dunn, 1985). In their research comparing three phonological analysis procedures (APP-R, NPA, and PPACL), Paden and Moss (1985) demonstrated vividly the intelligibility issue inherent in connected-speech sampling. of the eight potential subjects, ages $4: 11$ to $10: 7$, the connected-speech samples of five could not be analyzed due to poor intelligibility. These five subjects also received the five highest deviancy scores as analyzed by the APP-R (Hodson, 1986), placing them at high-severe and profound severity levels. This, in itself, they asserted, raised questions regarding the benefits of connected-speech sampling, adding that "these data support the observation that the highly unintelligible child can be successfully assessed only via elicited single words" (p. 105).

Intelligibility factors, however, do not form the sole basis for the selection of single-word assessment procedures. Hodson and Paden (1983) maintained that single-word elicitation is advantageous when compared to connected speech because it provides a better opportunity to examine a broader range of phonemes in a variety of positions, removes the potential for vocabulary constraints which can limit 
diversity of sound production, and provides assessment of progress, and consequently clinician accountability, through the use of an invariable word list. Additionally, a single-word articulation test eliminates the potential for selection avoidance due to the examiner's more rigid control of test stimuli and topic, provides normative data which can be used to establish severity ratings (an important prognostic indicator [Bankson \& Berntha1, 1983]), and requires less time to administer than a connected-speech sample (Bankson \& Berntha1, 1983; Paden \& Moss, 1985). For clinicians concerned about time constraints, Paden \& Moss went on to demonstrate that administration times for connected-speech samples and singleword articulation tests had a ratio of $2: 1$.

Although many proponents of assessment through single-word elicitation agree that connected-speech production may provide more total information when intelligiblity does not preclude its use, questions arise as to whether the difference in results between the two sampling procedures will lead to different management decisions. In their study comparing two analysis procedures for phonological impairment (single word and connected speech elicited by the materials comprising the APP-R), Andrews and Fey (1986) concluded that although more phonological processes were observed in connected speech, the similarities in performance in the two contexts were far greater than the differences and clinical decisions based on these results would be the same. Of the 14 moderately to profoundly phonologically impaired subjects, aged $2: 8$ to $6: 1$, in their study, none were assigned different severity ratings when assessed under the two 
sampling conditions. Bankson and Bernthal (1982) found similar results in their study of 18 four-year-olds using the single-word and sentence-delayed imitation tasks of the PPA. Results from the two methods of elicitation did not differ significantly and indicated that "one method is as likely as another to facilitate the identification of processes or patterns that may be present in the speech of children" (p. 96). Paden and Moss (1985) drew similar conclusions from their research as well, stating "the processes [identified] were identical using either elicited one-word responses or words extracted from a speech sample" (p. 106). Although recomending further study utilizing a larger sample, they maintained that "for children with phonological disorders, the method of speech sampling does not alter the major processes which are revealed" (p. 106). DuBois and Bernthal (1978) noted a similar relationship in speech production under the two procedures, acknowledging that although they found a difference in the number of errors produced under each condition, the differences were not clinically significant and single-word elicitation would lead to similar assessment decisions. 
CHAPTER III

ME THODS

SUB JECTS

The sample for this study comprised nine subjects ranging in age from 4 years 1 month to 6 years 1 month who were receiving services from speech, language, and hearing clinics within the Portland metropolitan area. Criteria for subject selection included the following:

1. Written permission from the child's parent or guardian to participate in the study (Appendix A).

2. Normal unilateral hearing as measured by a pure tone audiometric hearing screening at $25 \mathrm{~dB} \mathrm{HL}$ for the frequencies of $500,1000,2000$, and $4000 \mathrm{~Hz}$.

3. Absence of documented neuromuscular impairment.

4. Sufficient speech and language to generate a connectedspeech sample.

5. Diagnosis of a phonological process disorder of moderate or greater severity as documented through the administration of APP-R (Hodson, 1986) and as scored by the Computer Analysis of Phonological Processes (CAPP) (Hodson, 1985). 


\section{INSTRUMENTATION}

A portable Beltone pure tone audiometer, model 120, with Beltone TDH 39 headphones was used to conduct the audiometric hearing screening. Test administration was recorded with a Sony audiocassette tape recorder, model $B M-17$, with an electret condenser flat microphone, model ECM-FOl. An IBM compatible computer capable of processing the software Programs to Examine Phonetic and Phonologic Evaluation Records (PEPPER) (Shriberg, 1986) was used to analyze the speech samples.

The Assessment of Phonological Processes - Revised (APP-R) (Hodson, 1986), a procedure which assesses the presence and severity of phonological processes, was used to determine eligibility for the study. A description of the APP-R is found in Chapter II. The Computer Analysis of Phonological Processes (CAPP) (Hodson, 1985), a computer software porogram developed to analyze productions elicited through the administration of APP-R, was used to score speech productions elicited through the APP-R. The program was executed by an Apple II computer.

The Goldman-Fristoe Test of Articulation (GFTA) (Goldman \& Fristoe, 1986) was used to elicit single-word and connected-speech samples from all subjects. It comprises three subtests: "Soundsin-Words," "Sounds-in-Sentences," and "Stimulability." The GFTA elicits both spontaneous and imitative productions in single words and conversational speech. 
The "Sounds-in-Words" subtest elicits 44 spontaneous, singleword productions comprising all consonants within the English language except $/ 3 /$ and 11 consonant blends. The authors state that $13 /$ was eliminated from consideration due to its infrequent use. Within this subtest, speech production is elicited by 35 colored pictures which the authors state "depict objects and activities that are familiar to young children" (Goldman \& Fristoe, 1986, p. 3).

The "Sounds-in-Sentences" subtest consists of two narratives which the examiner reads aloud while presenting corresponding picture stimuli. The first subtest is supported with five pictures and the second subtest utilizes four pictures. The subtest was designed to elicit connected, "conversational-type" speech.

The "Stimulability" subtest, which was not used for this study, tests the subject's ability to imitate modeled speech sound productions.

The Programs to Examine Phonetic and Phonologic Evaluation Records (PEPPER) (Shriberg, 1986), a computer software program capable of evaluating speech samples regarding phonemic, phonetic, and phonologic components, was used to assess the connected-speech ("Sounds-inSentences" subtest) and single-word production ("Sounds-in-Words" subtest) in terms of percentage of occurrence of phonological processes.

\section{PROCEDURES}

Testing Environment

All procedures were conducted in a well-lit room free from ambient noise and distractions, with five subjects (Nos. 1, 4, 5, 6, 
and 7) examined at the Portland State University Speech and Hearing Clinic and four subjects (Nos. 2, 3, 8, and 9) evaluated in their homes. Sessions were recorded on audiotape.

The hearing screenings were conducted with the child seated with his back to the examiner to insure that visual cues did not bias the response. The remaining procedures were conducted with the examiner and subject seated facing each other on opposing sides of a table corner.

\section{Test Administration}

Potential subjects were scheduled for individual appointments. The procedures were completed in one l-hour session (including a short break mid-way) by seven of the subjects (Nos. $1,2,3,4,7,8$, and 9). The remaining two subjects (Nos. 5 and 6 ) were given the hearing assessment and presented the APP-R in one 30 -minute session and completed the remaining procedures in a second 30 -minute session the following day.

Subsequent to a hearing screening, potential subjects were administered the APP-R to establish the presence of a phonologicalprocess disorder of moderate or greater severity. Following manual instructions, 50 objects were spontaneously named by the child. As the objects were named, sound errors were recorded on a form containing the correct, broad phonetic transcription.

Subsequent to the administration of the APP-R, two subtests of the GFTA were administered and the resulting data were included in the study, assuming the severity level revealed by the APP-R was 
consistent with established criteria. The "Sounds-in-Words" subtest was administered for elicitation of words produced in isolation and the "Sounds-in-Sentences" subtest was used to elicit data for sound production in connected speech. Following manual instructions, the subtests were presented in the order listed above.

The "Sounds-in-Words" subtest was administered following manual instructions; the examiner revealed the test plates in sequential order, following each picture with the instrument's established eliciting question or statement. Sound errors were recorded on a form containing the targeted, broad phonetic transcription (Appendix B).

The "Sounds-in-Sentences" subtest was administered utilizing the instrument's established narrative, although presentation of the picture stimuli pertaining to the narrative deviated from manual procedure in that the pictures were revealed and responded to individually rather than being presented in a complete sequence prior to the examinee's response. This modification was used to ease memory constraints involved in the retelling of an extended narrative. As each picture comprising the story was presented, the subject was requested to retell the portion of the narrative which had just been presented. If the child was reticent or produced a sparse connectedspeech sample, prompts were provided, such as asking questions and pointing to significant details within the test plates. Responses were phonetically transcribed, utterance by utterance, on the appropriate response form (Appendix C). With the tape recorder running, the examiner verbally glossed all productions the child made 
which appeared at the time to have the potential for being unintelligible upon audio playback. Transcription from the audiotapes was conducted within 24 hours.

Reliability

This investigator and a speech-language pathology graduate student experienced in the assessment of speech sound errors served as judges of reliability for this study. The judges reviewed the audiotapes, listening to 23 percent ( 10 words) of each subject's Sounds-in-Words subtest and a mean of 44 percent ( 2 utterances per picture stimuli, 18 total) of each subject's Sounds-in-Sentences subtest. Productions used for reliability measurement were selected randomly, with the first production in each subtest omitted from consideration. Agreement of .80 or better in both conditions was established for this study to be considered reliable. This standard of reliability was met under both conditions. Intra-rater reliability for "Sounds-in-Words" and "Sounds-in-Sentences" was 89 percent and 93 percent, respectively. Inter-rater reliability for these two sampling conditions was 84 percent and 83 percent, respectively.

\section{DATA MEASUREMENT AND ANALYSIS}

The data obtained from the two subtests were subsequently analyzed by computer using the PEPPER to identify the phonological proceses used under each condition (single word and connected speech) and the percentage of occurrence of each of those processes. 
Comparison of the two sampling conditions involved determining the degree of relationship between the severity ratings reflected by two samples. To illustrate this comparison, nine tables were prepared which outlined, for each phonological process, the actual number of occurrences, the potential number of occurrences, and the resulting percentage of occurrence, as calculated by the PEPPER. Each table reflected the above data for all subjects in both sampling methods. Subsequently, the percentage of occurrence values were assigned a severity rating in accordance with the rating scale shown in Table I.

\section{TABLE I}

RATING SCALES CORRESPONDING TO PERCENTAGE OF OCCURRENCE INTERVALS

Severity Rating

Mild

Moderate

Severe

Profound
Percent of Occurrence

$$
0.00-0.10
$$$$
0.11-0.30
$$$$
0.31-0.50
$$$$
0.51-1.00
$$

Rating Score

A comparison of severity ratings, instead of percentage of occurrence, was utilized for two reasons: (a) severity ratings are the basis upon which management decisions are generally made and (b) the potential number of occurrences may vary substantially between the two sampling methods, thereby subjecting the comparison to significant rounding errors which could result in inappropriate data and an erroneous management decision.

The Pearson Product-Moment Correlation Coefficient (Pearson $\underline{\text { })}$ was then computed for each phonological process to determine the 
relationship between the severity ratings assigned by each sampling method. In order to determine the significance of this relationship, the Pearson $I$ value was statistically compared with the one-tailed $t-$ test with the level of significance set at $p<.05$. 
CHAPTER IV

RESULTS AND DISCUSSION

\section{RESULTS}

The purpose of this study was to determine if single-word elicitation procedures used in the assessment of phonological processes would have highly similar results to those obtained through connected speech. The single-word and connected-speech productions of nine children, ages four through six years, were analyzed for the presence and severity of nine phonological processes. Data pertaining to these subjects is presented in Appendix $D$.

The data for percentages of occurrence, severity ratings, and

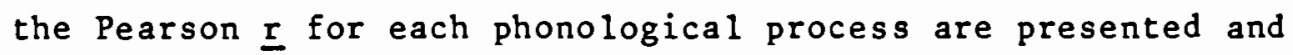
discussed on the following pages. An additional factor labeled "Rtg Dif." visually displays the difference in severity class ratings as determined by the two sampling methods.

The Pearson $\underline{r}$ computation was applied to the severity ratings to determine the strength of the relationship between the two testing methods. It was then compared with the one-tailed $\underline{t}-t e s t$ to establish its statistical significance at $p<.05$. Additionally, the data were evaluated to determine the levels of confidence at which the relationships would be considered significant. With a sample comprising nine subjects, only those phonological processes having 
Pearson $\underline{r}$ values greater than .582 can be considered as being statistically related (Clayton, 1984). The strength of the relationship depicted by the Pearson $\underline{r}$ correlation was described by Guilford

\section{(1965) as follows:}

$$
\begin{aligned}
\text { Less than } .20: & \text { Slight - Almost negligible } \\
.20-.40: & \text { Low - Definite but small } \\
.40-.70: & \text { Moderate - Substantial } \\
.70-.90: & \text { High - Marked } \\
.90-1.00: & \text { Very high - Very dependable }
\end{aligned}
$$

In this study, the variability of phonological-process severity ratings for the connected-speech samples was compared to that of the

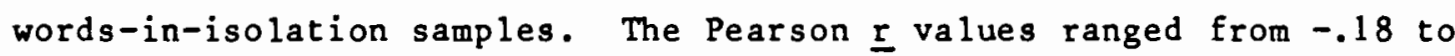
.90 , excluding two processes whose values were not computable. For these phonological processes, initial consonant deletion and assimilation (Tables II and III), the percentages of occurrences in the single-word procedure all resulted in a mild severity rating. With no variability upon which to compare the two sampling methods, the Pearson $\underline{r}$ could not be determined.

The Pearson $\underline{r}$ coefficients for three other phonological processes ranged from -.18 to .44 indicating a slight to moderate correlation. These values do not, however, demonstrate a signficant statistical relationship at the .05 level. Instead, the level of significance ranged from .15 to .35 . The correlation of the phonological processes of stopping (Table IV), liquid simplification (Table V), and cluster reduction (Table VI) resulted in Pearson $\underline{I}^{\prime} s$ of $.25, .44$, and -.18 respectively. 
TABLE II

PERCENTAGE OF OCCURRENCE, SEVERITY RATING, AND PEARSON $\underline{r}$ CORRELATION FOR INITIAL CONSONANT DELETION IN TWO

SAMPLING CONDITIONS

Single Words

Percent of Occurrence Severity

Subject Ratio Percent Rating
Connected Speech

Percent of

Occurrence
Ratio Percent $\begin{gathered}\text { Severity Rating } \\ \text { Rating Dif. }\end{gathered}$

$7 / 36$

.19

$3 / 86$

$2 / 95$

.03

.01

$2 / 123 \quad .02$

$2 / 57 \quad .04$

$1 / 72 \quad .01$

$1 / 87 \quad .01$

$\frac{2179}{22 / 775} \quad \frac{.03}{.03}$

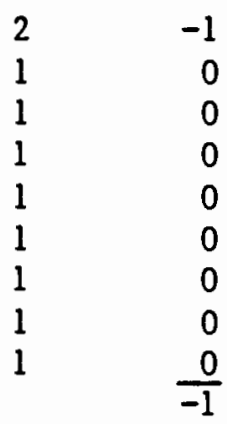

-1
0
0
0
0
0
0
0
0
-1

Pearson $\underline{I}=$ not computable

\section{TABLE III}

PERCENTAGE OF OCCURRENCE, SEVERITY RATING, AND PEARSON $\underline{\mathbf{r}}$ CORRELATION FOR ASSIMILATION IN TWO SAMPLING CONDITIONS

Single Words

Percent of

Occurrence Severity Ratio Percent Rating

$1 / 33$

.03

$1 / 33$

$1 / 33$

$0 / 33$

$1 / 33$

$1 / 33$

$2 / 33$

$1 / 33$

.03

.03

.00

.03

.03

.06

$0 / 33$

1
1
1
1
1
1
1
1
1

9
Totals

7

.03

$\frac{.00}{.03}$

Connected Speech
$\begin{aligned} & \text { Percent of } \\ & \text { Occurrence }\end{aligned}$
Ratio Peverity Rating
Rating Dif.

$\begin{array}{lll}0 / & 36 \quad .00\end{array}$

$\begin{array}{lll}5 / & 86 & .03\end{array}$

$\begin{array}{lll}0 / \quad 95 & .00\end{array}$

$0 / 140 \quad .00$

$3 / 123.01$

$\begin{array}{lll}0 / & 57 & .00\end{array}$

$\begin{array}{lll}3 / & 72 & .02\end{array}$

$\begin{array}{lll}1 / & 87 & .01\end{array}$

$\frac{3 / 79}{15 / 1404} \frac{.02}{.01}$ 


\section{TABLE IV}

PERCENTAGE OF OCCURRENCE, SEVERITY RATING, AND PEARSON $\underline{r}$ CORRELATION FOR STOPPING IN TWO SAMPLING CONDITIONS

Single Words

Percent of

Subject Occurrence Severity Ratio Percent Rating

$\begin{array}{ll}2 / 11 & .18 \\ 1 / 11 & .09 \\ 0 / 11 & .00 \\ 1 / 11 & .09 \\ 3 / 11 & .27 \\ 1 / 11 & .09 \\ 2 / 11 & .18 \\ 1 / 11 & .09 \\ 5 / 11 & .45 \\ 16 / 99 & .16\end{array}$

Totals

2
1
1
1
2
1
2
1
3

$2 / 23$

$0 / 53$

$6 / 52$

$0 / 98$

$15 / 56$

$1 / 30$

$0 / 40$

$9 / 43$

Connected Speech

$\frac{12 / 47}{45 / 442} \quad \frac{.26}{.10}$
Severity Rating Rating Dif.

$$
\text { Pearson } \underline{r}=.25 \text { Level of Significance }=P<.30
$$

\section{TABLE $V$}

\section{PERCENTAGE OF OCCURRENCE, SEVERITY RATING, AND PEARSON $\underline{r}$ CORRELATION FOR LIQUID SIMPLIFICATION IN TWO SAMPLING CONDITIONS}

Single Words

Percent of

Subject Ratio Percent $\begin{gathered}\text { Occurrence } \\ \text { Rating }\end{gathered}$

\begin{tabular}{|c|c|c|c|}
\hline \multicolumn{2}{|c|}{ Percent of } & \multirow{3}{*}{$\begin{array}{l}\text { Severity } \\
\text { Rating } \\
\end{array}$} & \multirow{3}{*}{$\begin{array}{l}\text { Rating } \\
\text { Dif. }\end{array}$} \\
\hline $0 c c$ & crence & & \\
\hline Ratio & Percent & & \\
\hline $2 / 5$ & .40 & 3 & -1 \\
\hline $2 / 7$ & .29 & 2 & 1 \\
\hline $7 / 16$ & .44 & 3 & 0 \\
\hline $8 / 11$ & .73 & 4 & -1 \\
\hline $8 / 12$ & .67 & 4 & -1 \\
\hline $2 / 6$ & .33 & 3 & 0 \\
\hline $1 / 6$ & .17 & 2 & 0 \\
\hline $5 / 12$ & .42 & 3 & 0 \\
\hline $8 / 12$ & .67 & 4 & -1 \\
\hline $43 / 87$ & .49 & & -3 \\
\hline
\end{tabular}

Connected Speech

Pearson $\underline{r}=.44 \quad$ Leve 1 of Significance $=p<.15$ 


\section{TABLE VI}

PERCENTAGE OF OCCURRENCE, SEVERITY RATING, AND PEARSON $\underline{\mathbf{r}}$ CORRELATION FOR CLUSTER REDUCTION

IN TWO SAMPLING CONDITIONS

Single Words

\begin{tabular}{cc}
\hline \multicolumn{2}{c}{$\begin{array}{c}\text { Percent of } \\
\text { Occurrence }\end{array}$} \\
\cline { 1 - 1 } Ratio & Percent \\
\cline { 1 - 1 } $8 / 10$ & .80 \\
$9 / 10$ & .90 \\
$9 / 10$ & .90 \\
$6 / 10$ & .60 \\
$8 / 10$ & .80 \\
$5 / 10$ & .50 \\
$6 / 10$ & .60 \\
$3 / 10$ & .30 \\
$\frac{8 / 10}{62 / 90}$ & .80 \\
\hline & .69
\end{tabular}

Connected Speech

\begin{tabular}{ll}
\hline $\begin{array}{l}\text { Percent of } \\
\text { Occurrence }\end{array}$ & $\begin{array}{l}\text { Severity Rating } \\
\text { Ratio Percent }\end{array}$ \\
\hline
\end{tabular}

$8 / 11 \quad .73$

$30 / 35 \quad .86$

$10 / 22 \quad .45$

$28 / 54 \quad .52$

$29 / 39 \quad .74$

$15 / 28 \quad .54$

$16 / 21 \quad .76$

$13 / 25 \quad .52$

$\frac{20 / 26}{169 / 261} \quad \frac{.77}{.65}$

\begin{tabular}{rr}
4 & 0 \\
4 & 0 \\
3 & -1 \\
4 & 0 \\
4 & 0 \\
4 & -1 \\
4 & 0 \\
4 & -2 \\
4 & 0 \\
\hline & -2
\end{tabular}

Pearson $\underline{r}=-.18 \quad$ Level of Significance $=p<.35$

The comparison of the severity ratings in four phonological processes did result in statistically significant relationships, at or beyond the .05 level, between the single-word and connected-speech samples. The Pearson $\underline{r}$ coefficient for unstressed syllable deletion was .66 , reflecting a moderate relationship (Table VII). The coefficient for velar fronting was slightly higher at .70 (Table VIII). A high correlation for final consonant deletion was indicated by a Pearson $\underline{r}$ value of .87 (Table IX). Palatal fronting demonstrated the highest correlation at .90 (Table X). 


\section{PERCENTAGE OF OCCURRENCE, SEVERITY RATING, AND PEARSON $\underline{T}$ CORRELATION FOR UNSTRESSED SYLLABLE DELETION \\ IN TWO SAMPLING CONDITIONS}

Single Words

\begin{tabular}{ll}
\hline Percent of & \\
Occurrence & Severity
\end{tabular}

Subject Ratio Percent Rating

$4 / 22 \quad .18$

$2 / 22 \quad .09$

$1 / 22$

$1 / 22$

$0 / 22$

$0 / 22$

$2 / 22$

$0 / 22$

9
Totals $\frac{0 / 22}{10 / 198}$

Pearson $\underline{r}=.66$
Connected Speech

\begin{tabular}{|c|c|c|c|}
\hline \multicolumn{2}{|c|}{ Percent of } & \multirow{2}{*}{$\begin{array}{c}\text { Severity } \\
\text { Rating }\end{array}$} & \multirow{2}{*}{$\begin{array}{l}\text { Rating } \\
\text { Dif. }\end{array}$} \\
\hline Ratio & Percent & & \\
\hline $3 / 26$ & .12 & 2 & 0 \\
\hline $5 / 50$ & .10 & 1 & 0 \\
\hline $9 / 54$ & .17 & 2 & -1 \\
\hline $0 / 60$ & .00 & 1 & 0 \\
\hline $3 / 48$ & .06 & 1 & 0 \\
\hline $0 / 37$ & .00 & 1 & 0 \\
\hline $2 / 31$ & .06 & 1 & 0 \\
\hline $5 / 50$ & .10 & 1 & 0 \\
\hline $1 / 32$ & .03 & 1 & $\underline{0}$ \\
\hline $28 / 388$ & .07 & & $-\bar{l}$ \\
\hline
\end{tabular}

\section{TABLE VIII}

PERCENTAGE OF OCCURRENCE, SEVERITY RATING, AND PEARSON $\underline{\mathfrak{r}}$ CORRELATION FOR VELAR FRONTING IN

TWO SAMPLING CONDITIONS

Single Words

Percent of Occurrence Severity

Subject Ratio Percent Rating
Connected Speech

Percent of Occurrence Severity Rating Ratio Percent Rating Dif.
$0 / 1 \quad .00$
$0 / 13 \quad .00$
$4 / 9 \quad .44$
$11 / 15 \quad .73$
$0 / 15 \quad .00$
$9 / 91.00$
$0 / 8 \quad .00$
$0 / 10 \quad .00$
$\frac{0 / 7}{24 / 87} \quad \frac{.00}{.28}$

3

0

$-1$

0

0

0

0

0

$\frac{0}{2}$

Pearson $\underline{r}=.70 \quad$ Level of Significance $=p<.03$ 
TABLE IX

PERCENTAGE OF OCCURRENCE, SEVERITY RATING, AND PEARSON $\underline{r}$ CORRELATION FOR FINAL CONSONANT DELETION

IN TWO SAMPLING CONDITIONS

\begin{tabular}{|c|c|c|c|c|c|c|c|}
\hline \multirow[b]{3}{*}{ Subject } & \multicolumn{3}{|c|}{ Single Words } & \multicolumn{3}{|c|}{ Connected Speech } & \multirow{3}{*}{$\begin{array}{l}\text { Rating } \\
\text { Dif. }\end{array}$} \\
\hline & \multicolumn{2}{|c|}{$\begin{array}{l}\text { Percent of } \\
\text { Occurrence }\end{array}$} & \multirow{2}{*}{$\begin{array}{c}\text { Severity } \\
\text { Rating }\end{array}$} & \multicolumn{2}{|c|}{ Occurrence } & \multirow{2}{*}{$\begin{array}{l}\text { Severity } \\
\text { Rating } \\
\end{array}$} & \\
\hline & Ratio & Percent & & Ratio & Percent & & \\
\hline 1 & $1 / 18$ & .06 & 1 & $9 / 36$ & .25 & 2 & -1 \\
\hline 2 & $10 / 18$ & .56 & 4 & $37 / 73$ & .51 & 4 & 0 \\
\hline 3 & $2 / 18$ & .11 & 2 & $12 / 61$ & .20 & 2 & 0 \\
\hline 4 & $0 / 18$ & .00 & 1 & $0 / 113$ & .00 & 1 & 0 \\
\hline 5 & $4 / 18$ & .22 & 2 & $16 / 113$ & .14 & 2 & 0 \\
\hline 6 & $0 / 18$ & .00 & 1 & $0 / 55$ & .00 & 1 & 0 \\
\hline 7 & $1 / 18$ & .06 & 1 & $8 / 51$ & .16 & 2 & -1 \\
\hline 8 & $1 / 18$ & .06 & 1 & $5 / 63$ & .08 & 1 & 0 \\
\hline 9 & $1 / 18$ & .06 & 1 & $7 / 64$ & .11 & 2 & -1 \\
\hline Totals & $2 \overline{0 / 162}$ & $\overline{.12}$ & & $\overline{95 / 629}$ & .15 & & -3 \\
\hline
\end{tabular}

Pearson $\underline{r}=.87$ Leve 1 of Significance $=p<.01$

TABLE X

PERCENTAGE OF OCCURRENCE, SEVERITY RATING, AND PEARSON $\underline{r}$ CORRELATION FOR PALATAL FRONTING

IN TWO SAMPLING CONDITIONS

Single Words

Percent of

Subject Ratio Percent $\begin{gathered}\text { Severity } \\ \text { Rating }\end{gathered}$

$0 / 4 \quad .00$

$0 / 4 \quad .00$

$0 / 4 \quad .00$

$1 / 4 \quad .25$

$0 / 4 \quad .00$

$0 / 4 \quad .00$

$0 / 4 \quad .00$

$0 / 4 \quad .00$

9

Totals

1
Connected Speech

$\begin{aligned} & \text { Percent of } \\ & \text { Occurrence }\end{aligned}$
Ratio Percent
Rating Rating
Rif.

$0 / 5 \quad .00$

$1 / 8 \quad .13$

$3 / 10 \quad .30$

$6 / 11 \quad .55$

$0 / 10 \quad .00$

$0 / 4 \quad .00$

$0 / 5 \quad .00$

$0 / 10 \quad .00$

$\frac{0 / 9}{10 / 72} \quad \frac{.00}{.14}$
0

$-1$

$-1$

$-2$

0

0

0

0

$\frac{0}{-4}$

Pearson $\underline{r}=.90 \quad$ Level of Significance $=p<.01$ 


\section{DISCUSSION}

With the limitation of this study to a sample comprising subjects exhibiting a phonological disorder of moderate or greater severity, and with the small sample size, the possible variability of the severity ratings within each individual phonological process was inherently limited. As a result, the effectiveness of the Pearson $\underline{r}$ correlation coefficient as a measure of the strength of the relationship between phonological processes evaulated using single-word and connected-speech samples appears to have been diminished.

Initial Consonant Deletion and Assimilation

In evaluating the similarities and differences between the two sampling methods for assessing the severity of initial consonant deletion and assimilation, the Pearson $\underline{r}$ coefficient was not applicable. As indicated on Tables II and III, with one exception, the severity ratings within both the single-word and running-speech samples were identical for each subject. As a result, with no variation within the sampling methods, the Pearson $\underline{r}$ could not identify a relationship. Visual examination of the data, however, suggests a high degree of consistency between the two sampling procedures in that they were almost identical.

\section{Initial Consonant Deletion}

When evaluating initial consonant deletion, none of the subjects produced an initial consonant deletion in the single-word sample (Table II). In the connected-speech procedure, each of the subjects 
produced initial consonant deletions, but eight of the nine subjects did not produce a sufficient number of deletions to initiate a change in the severity rating from that assigned by the single-word method. The mean percentage of occurrence for the single-word method was 0 percent while the mean percentage of occurrence for the connectedspeech method was 3 percent. With similar mean percentages of occurrence and consistent severity ratings for eight of the nine subjects, it appears that the single-word method may be accurate in reflecting the severity rating of inital consonant deletion.

\section{Assimilation}

Similar results occurred for the assessment of assimilation. The sampling methods were 100 percent consistent in their evaluation of the severity ratings. The mean percentages of occurrence for single word and connected speech were 3 percent and 1 percent, respectively. As with initial consonant deletion, it appears that the single-word method may provide an accurate rating of the severity of assimilation.

\section{Stopping}

The two sampling methods were not as closely related when determining the severity of stopping (Table IV). The Pearson $\underline{r}$ coefficient of .25 reflects a low correlation not sufficient to be considered statistically significant. The mean percentages of occurrence for single word and connected speech for this process, however, were 16 percent and 10 percent, respectively, suggesting that results from the two methods may be more similar than the correlation indicates. 
Visual evaluation of the two procedures reveals that five of the nine subjects were assigned different severity ratings by the two sampling procedures for this process. Of these inconsistencies, three could possible be attributed to rounding error and the location of the demarcation line between the mild and moderate severity ratings. Subjects 1 and 3 produced connected speech percentages of occurrence of .09 and .12 , respectively, while subject 8 produced a .09 singleword percentage of occurrence. With the division between the mild and moderate severity ratings established at .10 , a very slight change in the production of the stopping process could significantly change the assigned severity rating. Additionally, subject 7 demonstrated an interesting characteristic in that speech production in single words identified two occurrences of this process while the connected-speech sample, which was nearly four times longer, revealed no occurrence of this process. Visual examination of the two speech samples for this subject revealed that the two phonemes on which stopping occurred in the single-word method were either omitted or substituted in the connected speech sample.

Differences inherent in the two sampling methods could also have had an effect upon the degree to which the process of stopping was produced, but it was unexpected that this process would be used more frequently in single-word production than in connected speech. On the basis of the data as a whole, it appears that the single-word procedure can provide a good general evaluation of the severity of stopping, but connected speech may be more appropriate if a more comprehensive assessment is desired. 


\section{Liquid Simplification}

The Pearson $\underline{r}$ of the two sampling methods for liquid simplification was .44 , exhibiting a moderate relationship, but still insufficient to be deemed a statistically significant relationship (Table v). Visual inspection of the data discloses that four of the nine subjects were assigned different severity ratings by the two sampling procedures for this process. In each case, at least one of the percentage-of-occurrence values fell on or near the delineation between severity ratings. An additional factor was the limited opportunity (four occasions) for the production of this process in the GFTA "Sounds-in-Words" subtest. As a result, both the Pearson $\underline{r}$ correlation and a visual assessment of the data could be significantly impacted by a slight change in the severity ranges or the addition of supplemental words to the GFTA "Sounds-in-Words" subtest.

As with the processes of stopping, and cluster reduction (to be discussed later), it would be expected that the requirements for increased muscular coordination would result in an increased incidence of liquid simplification in connected speech, as was the case in this instance. However, tendencies toward selection avoidance could also be expected, which would have resulted in a lower percentage of occurrence in connected speech as was the case in stopping and cluster reduction. As with the evaluation of stopping, it appears that the single-word sampling method can provide a good general indication of the severity, but a connected-speech sample may be more appropriate for detailed assessments. 


\section{Cluster Reduction}

The consistency between the single-word and connected-speech sampling procedures in the assessment of cluster reduction was highly susceptible to the delineation of the severity ranges (Table VI). On the basis of the severity ranges established for this study, the Pearson $\underline{r}$ correlation coefficient was -.18 , reflecting a slight correlation and indicating that as the rating severity increased in one sampling method, the other method's severity rating would be expected to decrease.

A visual assessment of the data contradicts this expected trend. The data illustrate mean percentages of occurrence for the singleword and connected-speech procedures of 69 percent and 65 percent, respectively. Six of the nine severity ratings were consistent between the two sampling methods, suggesting a close association between single-word and connected-speech production. Of the three subjects assigned different severity ratings, two were significantly affected by the designated rating borders. Subject 6 produced a percentage of occurrence of 50 percent in the single-word procedure and a percentage of occurrence of 54 percent in the connected-speech sample. This resulted in differing severity ratings assessed by the two methods when an effective difference was not present. The consistency of the severity ratings for subject 8 was also adversely affected by the demarcation lines. The percentages of occurrence fell on the upper limit of the moderate classification and near the lower limit of the profound classification, thereby resulting in a two-class differentiation when the actual discrepancy was not that extreme. 
The difference in percentages of occurrence between the two samp1ing procedures was surprising. Connected speech would be expected to produce more instances of cluster reduction, not only because of the increased articulomotor difficulty inherent in producing more words continuously (thereby encouraging simplification of speech through reduction), but also because coarticulation can create additional clusters when abutting words ending and beginning with consonants are produced. In this instance, however, single words identified a higher percentage of occurrence of cluster reduction than did connected speech, suggesting that selection avoidance or other unknown factors may have affected the connected-speech sampling procedure.

In an effort to quantify the impact of the placement of the range delineations on this phonological process, the Pearson $\underline{r}$ correlation was recalculated with the line between severe and profound shifted from between .50 and .51 to between .55 and .56 . Following this small change, the correlation coefficient increased substantially from -.18 to .56 while the level of significance improved from .35 to .10 .

It is apparent from this analysis that the limited variability of the subjects' severity along with the impact of the severity-range delineations in this study, had a significant effect on the magnitude of the Pearson $\underline{r}$ correlation coefficient. Keeping in mind the visual data and the shift in the Pearson $\underline{r}$ and significance level values caused by a minor change in the rating borders, it appears that 
the single-word sampling procedure may provide a good indication of the actual severity of a subject's use of cluster reduction.

\section{Unstressed Syllable Deletion}

Table VII illustrates the assessments of the two sampling methods for unstressed syllable deletion. The Pearson $\underline{\mathbf{r}}$ was determined to be .66 indicating a moderate relationship sufficient to be statistically significant at the .05 level. A visual evaluation of the data supports the Pearson r calculation. The mean percentages of occurrence for single word and connected speech were 5 and 7 percent, respectively. The two sampling methods assessed eight of the nine subjects consistently. The one subject differing in assessment results involved a percentage-of-occurrence differentiation between 5 and 17 percent. With similar Pearson $\underline{r}$ and visual evaluations, it appears that the single-word sampling method can provide an accurate assessment of the severity of a subject's use of unstressed syllable deletion.

\section{Velar Fronting}

The Pearson $\underline{r}$ calculation for velar fronting produced a coefficient of .70 for a significantly high degree of dependability (Table VIII). Seven of the nine subjects were assessed equal ratings through the two methods. Subject 1, however, produced only one utterance with the potential for velar fronting during connected speech, while the single-word percentage of occurrence of this process was three out of five. As a result, the severity ratings 
assessed in the two sampling procedures for this subject were significantly different, ranging from mild to profound. As the potential opportunities for the occurrence of velar fronting by the other subjects was much greater (ranging from 7 to 15), an effort to evaluate the strength of the relationship between the two sampling techniques without the influence of subject 1 was initiated. The Pearson $\underline{r}$ was recomputed to exclude the subject 1 data and resulted in a new correlation coefficient exhibiting an increase to a very dependable value of .97 . A visual examination of the data confirms this nearly perfect correlation. Seven of the eight subjects (excluding subject 1) were assessed with equal severity ratings by both methods covering the full range of classifications from mild to profound. On this basis, it appears that the single-word sampling method can provide an excellent assessment of the incidence of the velar-fronting phonological process.

Final Consonant Deletion

The Pearson $\underline{r}$ correlation coefficient for final consonant deletion was statistically significant at .87 , reflecting a high correlation (Table IX). Covering the full range of severity ratings, the two sampling methods agreed on assessment values for six of the nine subjects. The discrepancies associated with the remaining three subjects were relatively minor. As with the velar fronting assessment, it appears that the incidence of final-consonant deletion can also be accurately assessed by using the single-word sampling procedure. 
Palata 1 Fronting

The relationship of the single-word and connected-speech sampling methods was greatest for palatal fronting (Table $X$ ). The Pearson $\underline{r}$ was statistically significant at .90 indicating a very high relationship with a level of significance of $p<.01$. A visual evaluation of the data, however, did not result in as strong a conclusion. Eight of the nine subjects failed to produce any palatal fronting during the single-word procedure. The ninth subject produced only one occurrence for a 25 percent (1/4) percentage of occurence value. This subject also produced a 55 percent (6/11) percentage of occurrence in connected speech. From a visual evaluation, it is apparent that the only subjects assessed with equal severity ratings through the two sampling methods were those subjects who did not produce any palatal fronting. An additional factor contributing to the uncertain nature of the data is the relatively small potential for the production of palatal-fronting phonological processes in the two GFTA subtests. Due to the inconsistency between the visual and Pearson $\underline{r}$ evaluations, and the relatively low actual and potential occurrences of the process, it appears that a determination of the better method of assessing palatal fronting severity may not be possible from this study.

\section{Pearson $\mathbf{r}$}

After evaluating the relationship between the connected-speech and single-word sampling procedures, it was apparent that further discussion of the Pearson $\underline{r}$ correlation analysis and its influence in this study was required. With several of the phonological processes, 
the degree of consistency between the connected-speech and singleword techniques was affected by the boundaries of the severity ratings. To determine if these boundaries substantially altered the effective percentage-of-occurrence relationships, the Pearson $\underline{\mathbf{r}}$ correlation was also performed on the percentages of occurrence without the impact of the severity ranges. Table XI illustrates the resulting values.

\section{TABLE XI}

A COMPARISON OF THE PEARSON $\subseteq$ CORRELATIONS CALCULATED ON ASSIGNED SEVERITY RATINGS AND ACTUAL PERCENTAGES OF OCCURRENCE IN TWO SAMPLING CONDITIONS

Phonological Process

Initial Consonant Deletion Assimilation

Stopping

Liquid Simplification

Cluster Reduction

Unstressed Syllable Deletion

Velar Fronting

Final Consonant Deletion

Palatal Fronting
Severity

$\frac{\text { Range }}{\underline{\mathbf{r}}}$ LOS

$\mathrm{N} / \mathrm{C} \quad \mathrm{N} / \mathrm{C}$

$\mathrm{N} / \mathrm{C} \quad \mathrm{N} / \mathrm{C}$

$.25 \quad .30$

$.44 \quad .15$

$-.18 \quad .35$

.66

.70

.87

.90

.58 $\stackrel{.05}{<.03}$

$<.01$

$<.01$
Actual Percent of Occurrence $\underline{\underline{L}} \underline{\operatorname{LOS}}$ $\mathrm{N} / \mathrm{C} \quad \mathrm{N} / \mathrm{C}$ $.19 \quad .35$

$.59 \quad .05$

$.51 \quad .10$

$.45 \quad .15$

$.42 \quad .15$

$.80<.01$

$.88<.01$

$.85<.01$

Critical Value for Significance at $7 \mathrm{df}$ and $\mathrm{p}<.05$

.58

$\overline{\text { LOS }}=$ Level of Significance for One-tailed t-test. $\mathrm{N} / \mathrm{C}=$ Not computable.

As displayed above, with the exception of assimilation, stopping, cluster reduction, and unstressed syllable deletion, the Pearson $\underline{r}$ values and corresponding levels of significance were similar, whether calculated from the percentage-of-occurrence or the severity-range 
data. The Pearson $\underline{r}$ correlation of the percentage-of-occurrence data for assimilation was computable, but still was not consistent with a visual evaluation. The stopping correlation increased to a statistically significant level, supporting the visual assessment. The correlation for cluster reduction improved to a level commensurate with the shift noted in severity range boundaries previously discussed for this process. The Pearson $\underline{r}$ for unstressed-syllable deletion dropped below the statistically significant level when evaluating the percentages of occurrence. In this instance, the low percentage-ofoccurrence values contained relatively large variances and were affected by rounding errors, therefore reducing the dependability and the Pearson $\underline{r}$ correlation. Although large in relation to the data, these variances were not sufficient to change the severity rating or the manner in which the subject's phonological processes would be managed. After evaluating both methods of comparison, the use of severity ratings in this study appears to provide better data upon which to determine the most appropriate sampling procedure.

Conclusions

Phonological processes are most commonly assessed through connected-speech and single-word elicitation procedures. The literature reflects differing opinions regarding the most effective means of elicitation, and clinicians desiring to select the optimum procedure for their needs must evaluate not only the specific statistical differences previously noted, but consider the inherent advantages and disadvantages of each procedure as we 11. 
Connected-speech sampling has been noted by some to be the preferable mode of elicitation in that it is more natural due to its conversational context and provides for the coarticulatory influence of proximal sounds (Garber, 1986; Shriberg \& Kwiatkowski, 1980), but is found by many to be time consuming and ineffective when dealing with unintelligible children (Andrews \& Fey, 1986; Hodson \& Paden, 1983 ; Paden \& Moss, 1985). Although the influence of surrounding sounds is sacrificed when words are produced in isolation, many prefer elicitation through single words because it takes less time to administer and score and provides a known contextual base which aids in the evaluation of unintelligible children (Hodson \& Paden, 1983; Paden \& Moss, 1985). The results of this study provided the following conclusions regarding these points.

The presence of coarticulatory factors in connected speech is undeniable although the extent of this influence in the identification of phonological processes is questionable. The connected-speech sampling procedure utilized in this study was similar to the routine procedure outlined by Shriberg and Kwiatkowski (1985), placing it within a moderate range regarding examiner control. Despite the resulting communicative freedom available to the subjects, their connected-speech samples did not reflect a substantially increased utilization of phonological processes. While some processes in some subjects were identified through connected speech which were not detected through single-word elicitation, there were also instances in which single words were produced with processes which were not exhibited in connected speech. In all instances, the differences 
noted would not have led to different management decisions. Studies similar to this conducted by Andrews and Fey (1986), Bankson and Berntha1 (1982), and Paden and Moss (1985) support these findings, with results varying from no difference to a slightly increased sensitivity of identification in connected speech. As with the present study, these researchers stated that the method of speech sampling did not alter the major processes identified, did not lead to different severity rating classifications, and differences in management decisions would not occur under the two methods of elicitation. The literature provides little information regarding the relative time requirements between these two methods of elicitation. In their study, Paden and Moss (1985) noted that administration time requirements between connected-speech sampling and single-word elicitation was $2: 1$. Observations from the present study reflect similar findings. While assessment through single words for each subject consistently took approximately ten minutes to administer and ten minutes to score, administration time for the connected-speech samp1ing procedures varied, depending on the subject's intelligibility and ability. Time requirements for this procedure ranged from 15 to 25 minutes to administer and an additional 30 to 45 minutes to score. This time differentiation becomes critical for clinicians maintaining large caseloads and operating under heavy time constraints. Intelligibility factors must also be considered when selecting the most desirable method of elicitation. Hodson and Paden (1983) noted that single-word elicitation was often the only means a clinician had to examine the sound productions of highly unintelligible 
children and noted that within their study of eight subjects, the connected-speech samples of five could not be analyzed due to poor intelligibility. A similar experience was noted in a pilot study associated with the present research, when two examinees demonstrated such low intelligibility that their speech samples could not be evaluated. Additionally, of the nine subjects assessed, three produced connected-speech samples which were considerably less intelligible than the sample they produced through single words. Obviously, the ability to adequately analyze the phonological processes utilized by an individual is greatly reduced when the speech they produce cannot be understood.

While it cannot be stated unequivocally that elicitation through single words will consistently identify all phonological processes in all individuals to the same extent that is noted in connected speech, the results of this study indicate that single-word assessments do provide clinicians with a valid representation of the phonological processes displayed by their clients. 
CHAPTER V

SUMMARY AND IMPLICATIONS

SUMMARY

The purpose of this study was to determine if single-word elicitation procedures used in the assessment of phonological processes would have highly similar results to those obtained through connected speech. Connected-speech sampling provides a medium for natural production with coarticulatory influence, but can be timeconsuming and impractical for clinicians maintaining heavy caseloads or working with highly unintelligible children. Elicitation through single words requires less time than a connected-speech sample and may be more effective with highly unintelligible children due to a known context, but lacks the influence of surrounding words. Given the inherent differences between these two methods of elicitation, knowledge of the relative effectiveness of single-word and connectedspeech sampling may become an issue for clinicians operating under severe time constraints and requiring an efficient and effective means of assessing phonological processes.

The sample for this study comprised nine children, aged 4 years 1 month to 6 years 1 month, selected from speech, language, and hearing clinics within the Portland metropolitan area. Each subject exhibited a phonological process disorder of moderate or greater 
severity. Additional selection criteria included normal unilateral hearing and the absence of documented neuromuscular impairment. Each subject was administered two assessment instruments. The Assessment of Phonological Processes - Revised (APP-R) (Hodson, 1986) was used to establish the presence of a phonological process disorder meeting eligibility criteria (moderate or greater severity) and the GoldmanFristoe Test of Articulation (GFTA) (Goldman \& Fristoe, 1986) "Soundsin-Words" and "Sounds-in-Sentences" subtests were administered to elicit single-word and connected-speech samples.

The two types of speech samples were then evaluated by the Programs to Examine Phonetic and Phonologic Evaluation Records (PEPPER) (Shriberg, 1986) to determine the percentages of occurrence for each phonological process. Each subject's production of phonological processes under the two conditions was assigned a severity rating from 1 to 4 and the resulting values were statistically compared utilizing the Pearson $\underline{r}$ Product-Moment Correlation Coefficient (Pearson $\underline{r}$ ). Four of the nine phonological processes, i.e., unstressed syllable deletion, velar fronting, final consonant deletion, and palatal fronting, were found to be related sufficiently to be statistically significant at the $\mathrm{p}<.05$ level, with Pearson $\underline{r}^{\prime} \mathrm{s}$ ranging from .66 to .90 . Two processes, i.e., initial consonant deletion and assimilation, showed no variance and thus could not be compared with the Pearson r. The three remaining processes, i.e., stopping, liquid simplification, and cluster reduction were not found to be related at a statistically significant level. 
The Pearson $\underline{r}$ computation was not always supported by a visual evaluation. Upon thorough analysis, it became apparent that the limitation of the subjects to individuals exhibiting phonological processes of a moderate or greater severity resulted in a corpus of data so homogeneous that the relevance of the Pearson $\underline{r}$ correlation was diminished.

On the basis of a combined Pearson $\underline{r}$ and visual appraisal, the significance of the similarities between the single-word and connected-speech sampling methods became more apparent. For six of the nine processes, the single-word samples produced assessments of the incidence of phonological processes similar to those identified by the connected-speech sample. Although the accuracy of the singleword method was not as great for the three remaining processes, results were sufficiently comparable to provide clinicians with confidence that single-word elicitation provides an acceptable mode of assessment in most instances.

\section{IMPLICATIONS}

\section{Clinical}

When selecting between single-word and connected-speech methods of elicitation in the assessment of phonological processes, clinicians must appraise not only the inherent advantages and disadvantages within each procedure, but must consider as well how the results from the two modes of elicitation compare. Additionally, consideration should be given to the intended use of the assessment results. 
A comparison of the two sampling methods suggests that while a difference does exist, the difference does not involve all processes, nor does it appear to be so substantial as to become a determining factor when making management decisions. If a highly sensitive assessment of the degree of severity for each phonological process is required and sufficient time is available, connected-speech sampling may be the desired mode. However, for clinicians working under heavy time constraints with children who are highly unintelligible, have short attention spans, or are otherwise socially reticent communicators, the single-word assessment appears to be a viable option.

The intended use of the resulting data should also be a consideration when selecting an assessment procedure. Clinicians desiring a general understanding of a client's phonological system for remediation purposes might have less strict selection criteria than the clinician establishing final treatment priority lists. Additionally, individuals working within a clinical setting may have different data requirements than those doing research.

\section{Research}

One research implication suggested by this study is the need for an increased knowledge base regarding correlations between phonological processes generated through connected speech under different levels of examiner control. For example, knowledge regarding the effectiveness of connected speech elicited in a direct imitation milieu would be beneficial: if it were found to be a sensitive measure, it could provide clinicians with the benefits found in 
continuous speech production while decreasing time requirements associated with this method. Additionally, assessment difficulties encountered with highly unintelligible and reticent children could be decreased.

An in-depth analysis of the relative time required to assess the speech of phonological-process-disordered children through single words and connected speech would also be valuable. Individuals working within the field recognize that connected speech is a more lengthy assessment procedure, but a factual time assessment of the actual time requirements of the two methods would be beneficial.

A follow-up evaluation comparing a clinician's original singleword assessment and subsequent observations of processes exhibited during the first few weeks of management may be of value to determine if processes evolved in the management phase were not noted in the original assessment. 


\section{REFE RENCES}

Andrews, N., and Fey, M. (1986). Analysis of the speech of phonologically impaired children in two sampling conditions. Language, Speech, and Hearing Services in Schools, 17, 187-198.

Bankson, N., and Bernthal, J. (1982). A comparison of phonological processes identified through word and sentence imitation tasks of the PPA. Language, Speech, and Hearing Services in Schools, 13, 96-99.

Bankson, N., and Bernthal, J. (1983). In defense of the traditional articulation test battery. Seminars in Speech and Language, 4 , 289-296.

Benjamin, B., and Greenwood, J. (1983). A comparison of three phonological assessment procedures. Journal of Childhood Communication Disorders, $\underline{7}, 19-27$.

Clayton, K. (1984). An introduction to statistics for psychology and education. Columbus: Charles E. Merrill.

Darley, F., and Spriestersbach, D. (1978). Diagnostic methods in speech pathology. New York: Harper \& Row.

DuBois, E., and Bernthal, J. (1978). A comparison of three methods for obtaining articulatory responses. Journal of Speech and Hearing Disorders, 43, 295-305.

Edwards, M. (1983). Issues in phonological assessment. Seminars in Speech and Language, $4,351-374$.

Faircloth, M., and Faircloth, S. (1970). An analysis of the articulatory behavior of a speech-defective child in connected speech and in isolated-word responses. Journal of Speech and Hearing Disorders, 35, 51-61.

Garber, N. (1986). A phonological analysis classification for use with traditional articulation tests. Language, Speech, and Hearing Services in Schools, 17, 253-261.

Garn-Nunn, P. (1986). Phonological processes and conventional articulation tests: Considerations for analysis. Language, Speech, and Hearing Services in Schools, 17, 244-252. 
Goldman, R., and Fristoe, M. (1986). Goldman-Fristoe test of articulation. Circle Pines, MN: American Guidance Press.

Guilford, J. (1965). Fundamental statistics in psychology and education ( 4 th ed.). New York: McGraw-Hill.

Hodson, B. (1985). Computer analysis of phonological processes. Stonington, IL: PhonoComp.

Hodson, B. (1986). The assessment of phonological processes revised. Danville, IL: Interstate Printers \& Publishers.

Hodson, B., and Paden, E. (1983). Targeting intelligible speech. San Diego: College-Hill Press.

Ingram, D. (1981). Procedures for the phonological analys is of children's language. Baltimore: University Park Press.

Ingram, D. (1983). The analysis and treatment of phonological disorders. Seminars in Speech and Language, 4, 375-388.

Johnson, J., Winney, B., and Pederson, O. (1980). Single word versus connected speech articulation testing. Language, Speech, and Hearing Services in Schools, 11, 175-179.

Kahn, L., and Lewis, N. (1986). Kahn-Lewis phonological analysis. Circle Pines, MN: American Guidance Service.

Klein, H. (1984). Procedures for maximizing phonological information from single-word responses. Language, Speech, and Hearing Services in Schools, 15, 267-274.

Paden, E., and Moss, S. (1985). Comparison of three phonological analysis procedures. Language, Speech, and Hearing Services in Schools, 16, 103-109.

Pau1, R., and Shriberg, L. (1982). Associations between phonology and syntax in speech-delayed children. Journal of Speech and Hearing Research, 25, 536-547.

Shriberg, L. (1986). Programs to examine phonetic and phonologic evaluation records. Madison, WI: University of Wisconsin Madison.

Shriberg, L., and Kwiatkowski, J. (1980). Natural process analysis. New York: John Wiley \& Sons.

Shriberg, L., and Kwiatkowski, J. (1985). Continuous speech sampling for phonologic analysis of speech delayed children. Journal of Speech and Hearing Disorders, 50, 232-334. 
Stampe, D. (1969). The acquisition of phonetic representation. Papers from the 5th regional meeting, Chicago Linguistic Society, 443-454.

Stoe 1-Garmon, C., and Dunn, C. (1985). Normal and disordered phonology in children. Baltimore: University Park Press.

Weiner, F. (1979). Phonological process analysis. Baltimore: University Park Press.

Weiss, C., Gordon, M., and Lillywhite, H. (1987). Clinical management of articulatory and phonologic disorders (2nd ed.). Baltimore: Williams and Wilkins. 
APPENDIX A

CONSENT FORM FOR SUBJECT PARTICIPATION 
CONSENT FORM FOR SUBJECT PARTICIPATION

\section{Dear Parent:}

I am a graduate student at Portland State University in the Speech and Hearing Sciences Program. I am conducting research to determine the most effective and efficient means with which to assess a type of articulation disorder in children and would appreciate your permission to include your child in my study.

Children participating in this study will be given a hearing screening test and two tests assessing speech sounds. The speech sound tests will involve the naming of objects and pictures and the retelling of two short stories. The procedures, to be scheduled at your convenience, will require approximately 45 minutes to complete.

There will be no risk to your child through participation in this study and his/her name will not be used. You may withdraw your child from this study at any time without penalty and without jeopardizing any relationship you may have with Portland State University or your child's speech clinic. Although you or your child may not receive any direct benefit from participation in this study, increased knowledge could benefit others in the future. I will be supervised by Mary E. Gordon, Associate Professor at Portland State University.

Thank you for your consideration.

Susan Pinkerton

Signature of parent or guardian

Date signed

Child's full name

Child's birthdate

If you experience any problems that are the result of your participation in this study, please contact the secretary of the Human Subjects Resarch and Review Comittee, Office of Grants and Contracts, 303 Cramer Ha11, Portland State University, 725-3417. 


\section{APPENDIX B}

\section{GOLDMAN-FRISTOE TEST OF ARTICULATION}

SOUNDS-IN-WORDS SUBTEST 
59

GOLDMAN-FRISTOE TEST OF ARTICULATION

SOUNDS-IN-WORDS SUB TEST

Subject Birthrate Date Examiner

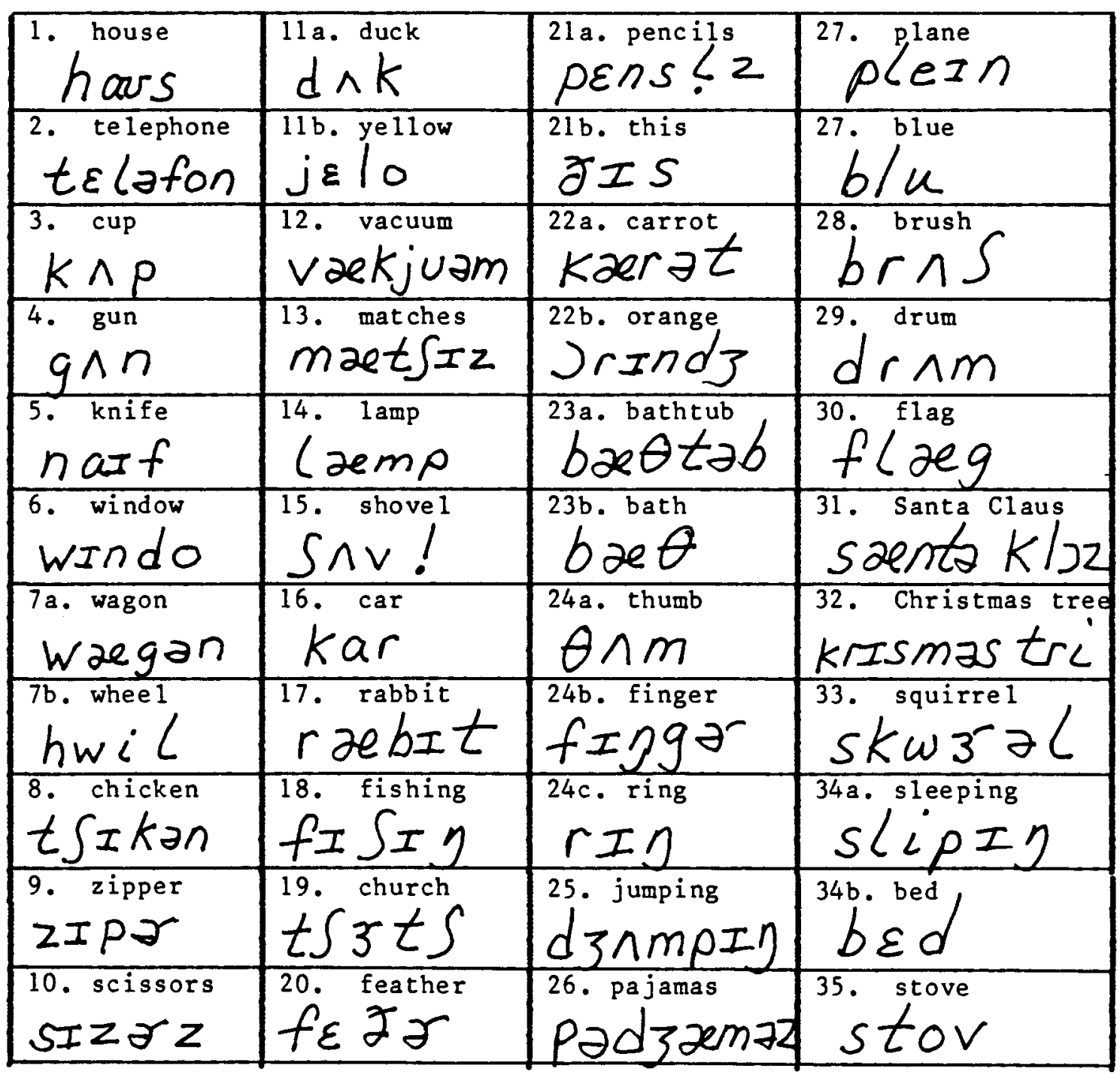




\section{APPENDIX C}

GOLDMAN-FRISTOE TEST OF ARTICULATION

SOUNDS-IN-SENTENCES SUBTEST 
GOLDMAN-FRISTOE TEST OF ARTICULATION

SOUNDS-IN-SENTENCES SUBTEST

Subject

Birthdate

Date

Examiner

Plate 36: Jerry playing drum ball wagon much noise Ut. 非 
SOUNDS-IN-SENTENCES SUB TEST

Sub ject

Birthdate

Date

Examiner

Plate 37: taking bath loses soap floor

Ut. 非

Plate 38: brushing toothpaste blue pajamas

UT. \# 
SOUNDS-IN-SENTENCES SUB TEST

Sub ject

Birthdate

Date

Examiner

Plate 39: yawns yellow light

Ut. 非

Plate 40: sleeping covers sheet

UT. 非 
SOUNDS-IN-SENTENCES SUBTEST

Sub ject

Birthdate

Date

Examiner

Plate 41: Jack Ricky going fishing glasses shirt zipper Ut. 非

Plate 42: bridge dog chasing squirrel UT. \# 
SOUNDS-IN-SENTENCES SUB TEST

Subject

Birthdate

Date

Examiner

Plate 43: catch fish four five thirteen they laugh very Ut. 非

Plate 44: house mother

UT. \# 


\section{APPENDIX D}

SEX, AGE, AND APP-R SCORES OF THE NINE SUBJECTS 
SEX, AGE, AND APP-R SCORES OF THE NINE SUBJECTS

\begin{tabular}{|c|c|c|c|c|c|}
\hline Subject & Sex & Age & $\begin{array}{c}\text { Average of } \\
\text { Phonological } \\
\text { Processes } \\
\end{array}$ & $\begin{array}{c}\text { Phonological } \\
\text { Deviancy } \\
\text { Score } \\
\end{array}$ & $\begin{array}{l}\text { Severity } \\
\text { Interval }\end{array}$ \\
\hline 1 & M & $6: 1$ & 40 & 55 & Severe \\
\hline 2 & $M$ & $5: 6$ & 52 & 62 & Profound \\
\hline 3 & $M$ & $4: 1$ & 41 & 46 & Severe \\
\hline 4 & F & $5: 11$ & 25 & 40 & Severe \\
\hline 5 & M & $4: 1$ & 48 & 53 & Severe \\
\hline 6 & M & $4: 4$ & 21 & 26 & Moderate \\
\hline 7 & F & $4: 11$ & 23 & 33 & Moderate \\
\hline 8 & $\mathbf{M}$ & $4: 1$ & 16 & 21 & Moderate \\
\hline 9 & $M$ & $4: 6$ & 33 & 38 & Moderate \\
\hline
\end{tabular}

APP-R: Hodson, 1986 